African Journal of Educational Studies in Mathematics and Sciences Vol. 16, No. 2, 2020

\title{
An Overview of Learning Cycles in Science Inquiry-based Instruction
}

\author{
C. B. Nicol ${ }^{1}$, E. Gakuba ${ }^{2} \&$ G. Habinshuti ${ }^{3}$
}

\begin{abstract}
While a plethora of researchers have acknowledged the importance of learning cycles as a model of instruction in a constructivist supported enquiry science education, the rising number of learning cycle models however raises compelling questions about validity, hence the need for a comprehensive overview and analysis of the comparative strengths and weaknesses of these models. This paper examined among the very many, four major learning cycles; 3E, 5E, 7E and 9E, on the scales of knowledge construction, to provide adequate information for decision making regarding their preference and use. While the $3 \mathrm{E}$ provides the very basic framework for expansion, it missed addressing the learners' initial dialogic engagement with teachers as well as summative evaluation of learning. Critical analysis informed the conclusion that there are three main goals common to the learning cycles under review namely; the development of conceptual understanding, process skills and critical thinking. A well-planned and implemented 5E model generally meets the inquirybased constructivist learning goals, although it is silent on transfer of knowledge outside of the classroom. This transfer of knowledge, provided for in the $7 \mathrm{E}$, is the major meaningful difference between $5 \mathrm{E}$ and $7 \mathrm{E}$. The three new phases introduced in the 9E, Echo, Emend and E-search, were assessed to be redundant. After a thorough needs assessment of the phases of the learning cycles under review, a six-phase learning cycle is proposed comprising Engage, Explore, Explain, Elaborate, Evaluate and Extend.
\end{abstract}

keywords: learning cycles, inquiry-based instruction, history of learning cycles, model of instruction

\section{Introduction}

The learning cycle is a model that structures and divides instruction into sequential phases that follow the pattern of the scientific inquiry process (Marek, 2008). According to Settlage (1999), the learning cycle provides both hands-on and minds-on learning opportunities which help learners develop independent reasoning abilities by deep reflection on classroom learning activities. It provides both teachers and learners with a unique experience of a more methodic approach to knowledge construction and creates greater

${ }^{1}$ Mr. Christian Bob Nicol (Corresponding author). PhD student in Chemistry Education at the African Center of Excellence for Innovative Teaching and Learning Mathematics and Science (ACEITLMS), College of Education, University of Rwanda. Email Address: cbnicol2009@gmail.com, Telephone Number: +250782379094;

${ }^{2}$ Dr. Emmanuel Gakuba, Lecturer of chemistry at the College of Education, University of Rwanda and belongs to the Department of Mathematics, Science and Physical Education.

${ }^{3}$ Dr. Gonzague Habinshuti, Lecturer and postgraduate coordinator at the School of Inclusive and Special Needs Education. Universitv of Rwanda.

Open Access article distributed under the terms of the Creative Commons Attributions License [CC BY-NC-ND 4.0] http://creativecommons.org/licenses/by-nc-nd/4.0. DOI: https://dx.doi.org/10.4314/ajesms.v16i.2.5 


\section{An Overview of Learning Cycles in Science Inquiry-based Instruction}

\section{B. Nicol, E. Gakuba \& G. Habinshuti}

accountability in the classroom. Structuring instruction in a way that maximizes learning outcomes by provoking learners' thinking and stimulating their interests in the subject is the way of the learning cycle (Quarareh, 2015).

Educational researchers have always aspired for an improvement in the academic achievement in learning by employing efficient instructional strategies (Odom \& Kelly, 2001) as it must be carefully considered what children learn and how they learn. There are many learning cycle models of instruction available in the literature constituting wide variations in the number of phases (Marek, 2008; Abell \& Brown, 2007). While it may serve a good purpose to divide instruction into phases, the increasing number of learning cycles and phases of instruction raises a compelling question about their practicability of implementation, hence an evaluative study of the comparative strengths and weakness of four major learning cycles was the focus of this paper. To this end, this paper sought to examine the rationale and educational needs for each of the four learning cycles and their phases: this was done by examining the phases of each in order to identify what similarities and differences account for their strengths and weaknesses. In this respect, and in order to set the basis for thorough comparative analysis, these four models are those which have names of the phases beginning with the letter "E".

\section{Method}

The literature was gathered from 42 sources comprising online journal articles, reports, conference proceedings and books; these were downloaded from databases including Google Scholar, Research for Life and ERIC. Search phrases included; learning cycles, scientific inquiry, history of learning cycles, $3 \mathrm{E}$ learning cycle, $5 \mathrm{E}$ learning cycle, $7 \mathrm{E}$ learning cycle and $9 \mathrm{E}$ learning cycle. As an overview, every article that adequately addressed at least one of the key words was included for this study. As such, out of 71 sources that were initially downloaded, 42 were deemed appropriate for inclusion. On the basis of the fact that this paper was committed to evaluating the learning cycles, the four learning cycles under review were used as the main topic headings for discussion in addition to a brief history of the learning cycles. The literature search was therefore essentially to develop the contents discussed under each of the topic headings. The discussion section generally viewed the four learning cycles and their phases in light of their critical necessity and alignment with educational theories.

\section{A Brief History of the Learning Cycle}

Everyone who has properly planned and delivered a lesson in sequential phases characterized by learners' maximum interaction with learning aids, their peers and with the teacher might have in some way used parts of the learning cycle. As this practice may have therefore existed in the classrooms long before Socrates came up with his inquiry mode of learning by leading his students to discover knowledge, it is difficult to ascertain who invented the learning cycle. However, many instructional models have existed, some of which are still related to new ones developed today Table 1 shows the names of the model and their respective phases as indicated by Bybee et al., (2006). According to Bybee et al. (2006), the Karplus and Thiers learning cycle was more advantageous to learning than the others, therefore, Karplus and Thiers became credited with the development of the learning cycle (Hanuscin \& Lee, 2008; Lawson, Abraham \& Renner, 1989; Withers, 2016).

Before inquiry-based instruction came to the limelight in the 20th century, science was 
African Journal of Educational Studies in Mathematics and Sciences Vol. 16, No. 2, 2020

Table 1 The Phases of Instructional Models in History

\begin{tabular}{|c|c|}
\hline Name of Model & Phases \\
\hline Herbert's instructional model & - Preparation, presentation, generalization, application \\
\hline Dewey’s instructional model & $\begin{array}{l}\text { - } \text { Sensing Perplexing Situations, Clarifying the Problem, } \\
\text { - } \text { Formulating a Tentative Hypothesis, Testing the } \\
\text { Hypothesis, } \\
\text { - Revising Rigorous Tests, Acting on the solution }\end{array}$ \\
\hline $\begin{array}{l}\text { Heiss, Obourn and Hoffman } \\
\text { Learning Cycle }\end{array}$ & $\begin{array}{l}\text { - Exploring the Unit, Experience Getting, Organization of } \\
\text { Application of Learning }\end{array}$ \\
\hline & - Application of Learning \\
\hline Atkins-Karplus model & - Invention, Discovery \\
\hline Karplus and Thiers model & - Exploration, invention, discovery \\
\hline
\end{tabular}

Source: Authors' review data, 2020

viewed as comprising facts that teachers gave out to the learners who needed to learn them by rote memorization (DeBoer, 2006), but the late 1950s saw a gradual shift in this paradigm with the launch of the "Alphabet Soup Project" in the USA, which included the Biological Science Curriculum Study (BSCS), the Chemical Education Improvement Study (Chem Study), the Science Curriculum Improvement Study (SCIS), the Elementary Science Study (ESS), the Physical Science Study Committee (PSSC Physics), and the Earth Science Curriculum Project (ESCP) (Lawson, Abraham and Renner, 1989). This was how the SCIS proposed the first learning cycle which comprised of the three phases listed in Table 1 (Karplus \& Their, 1967).

However, work towards developing the SCIS learning cycle started with research conducted by Karplus and another colleague of his, Atkins, between late 1950s and early 1960s: it was meant to craft a curriculum that could facilitate learners' easy connections of their conceptions to the new information acquired in school. The precursor to it was an offshoot from Jean Piaget's ideas of cognitive functioning, and comprised of only two parts; named Invention and
Discovery. Whereas Invention was intended for the teacher to introduce the concept, Discovery was meant for the students to identify new patterns and for the teacher to verify those patterns about the concepts (Lawson, Abraham \& Renner, 1989). In another research involving elementary school pupils, Karplus and Their realized that learners needed time and space for the exploration of a science topic with minimal teacher guidance (Hanley, 1997). Only then was the idea of a model of instruction that would be called the learning cycle conceived. In 1989, the BSCS led by Roger Bybee, conducted a study that was funded by International Business Machines (IBM) to design a new curriculum for teaching elementary school science. This study resulted in the development of the $5 \mathrm{E}$ learning cycle that built on the success of the SCIS learning cycle (Bybee et al., 2006). Many of the other learning cycle models that have been developed are direct derivatives of the SCIS learning cycle.

One important indication of inquiry in a classroom was the replacement of the textbooks and the teacher as ultimate sources of information on science with active engagement in hands-on activities. 


\section{An Overview of Learning Cycles in Science Inquiry-based Instruction}

\section{B. Nicol, E. Gakuba \& G. Habinshuti}

Nevertheless, Abell and Brown (2007) still suggest to teachers whose curriculums are textbook dominated to infuse inquiry-based instruction by starting the lesson with an activity (exploration) like an experiment, followed by reading the textbook for concept introduction, in accordance with the SCIS learning cycle. While it may look difficult to design an inquiry- type science lesson, the easiest way to do this is to adopt a learning cycle, which both represents the way scientists carry out an inquiry and is also patterned after the natural ways we solve problems in an inquiry (Abraham, 1997).

\section{Theories that are Consistent with the Learning Cycles Model}

The learning cycle as an instructional model is rooted in the constructivist learning theory, which, first identified and proposed by Swedish educationist, Jean Piaget holds that learners should be allowed time, space and resources to construct their knowledge rather than have authoritative sources giving them all the information. This way, the knowledge they build will last longer with them (Piaget, 1953). Richardson (2003) describes constructivist pedagogy as a process that continuously provides the room for individual and collective learners' growth and development as well as prepare learners in key areas of competencies needed for lifelong learning. However, for this pedagogy to be used effectively, the teacher's knowledge of the use of the constructivist theory is equally as important as the knowledge of the learner's level of attainment in the topic for instruction at any given point in the learning process (Powell \& Kalina, 2009).

Since learners always bring to class their conceptions or cognitive structures about a topic. If the information they receive (a new cognitive structure) is consistent with the existing information (existing cognitive structure), assimilation occurs. Otherwise, if the information conflicts with the existing cognitive structure, there is disequilibrium as a result of a disaccord between the different cognitive structures. In a process called reequilibration, the means by which there are a compromise and balance between the two cognitive structures, accommodation of the new cognitive structure is attained (Gok, 2014). Therefore, in a typical science classroom, learners are given an activity in an exploration phase of the learning cycle that is meant to raise questions in their minds leading to disequilibrium. Thereafter, in Concept Development or Explanation, accommodation or reequilibrium is attained (Marek, 2008). Clearly, cognitive processes are no doubts at the center of learning achievements.

In addition, the Generative Theory of Learning explains the process of learning as consisting of selecting materials relevant portions of the pool of information in a lesson, organizing them into a working memory and integrating it with the previous knowledge and experiences for construction of knowledge. It therefore prescribes more cognitive activities than behavioral ones for maximizing learning (Mayer et al.,2009). Reiff, Harwood and Philipson (2002) emphasize appropriate questioning techniques as major means of triggering cognitive processes in learners. However, questions and exploration that fall well outside of the learners' zone of proximal development might amount to heavy burden on the working memory, which Paas, Renkl and Sweller (2003) say is detrimental to learning.

Lawson Abraham and Renner (1989) presents two basic kinds of knowledge in cognitive science as declarative and procedural knowledge. They emphasize the need for every theory of instruction to indicate clearly how these will be addressed. 
This is what the learning cycle accomplishes. According to Ramsey (1993), the learning cycle is an excellent approach to building students' conceptual understanding through concrete experiences: it has been proven to be suitable for developing curriculums as well as for instruction, and is adaptable for use at various levels of educational attainments; elementary schools, secondary schools and universities (Renner \& Marek, 1988).

\section{The Three-phase Learning Cycle}

As stated earlier and elaborated in this section, the first theory of guided inquiry learning for science teaching became the product of the Science Curriculum Improvement Study in the 1960s, which element of teaching and learning. The concepts understood can then be extended, applied or expanded to demonstrate a firm grip on the acquired knowledge and skills. Following are the detail explanations of what the SCIS learning cycle entails.

\section{Exploration}

Usually either in pairs or small groups, learners are engaged in a purposeful exploration which involves availing learners with materials and resources for an activity: these may include an experiment, the building of a model, conducting simulations and, reading and comprehension for gathering needed information that could address the lingering question (Dass, 2015) in order that, by manipulation and

Table 2 The Evolution of the Three Phase Learning Cycle

\begin{tabular}{lclll}
\hline Author(s) & Year & Phase One & Phase Two & Phase Three \\
\hline Karplus and Their & 1967 & Exploration & Invention & Discovery \\
Karplus et al & 1977 & Exploration & Concept introduction & Concept application \\
Renner, Abraham and & 1985 & Exploration & Concept introduction & Expansion of idea \\
Birnie & & & & \\
Good and Lavoie & 1986 & Exploration & Concept introduction & Concept application \\
Abraham and Renner & 1986 & Exploration & Concept introduction & Expansion \\
Lawson & 1988 & Exploration & Term introduction & Concept application \\
\hline
\end{tabular}

Source: Authors' review data, 2020

organized instruction into three phases. These have come to be known as Exploration, Term Introduction and Concept Application. The names and what the phases represented was for a considerable period a matter of controversy. Table 2 shows how these names have evolved with time.

Throughout the development of the learning cycle, consensus among contributors about the need for the Exploration phase and the consistent emphasis for its placement in the sequence as the first step in science learning indicates its tremendous relevance to learning. It serves as the basis for further understanding the concepts as a fundamental observation, and through their actions and reactions, learners are able to map out learning points and construct patterns in their minds as well as generate data as they experience the new ideas (Cavallo \& Laubach, 2001). This new experience should raise learners' interests even more in the topic, raise questions in their minds and trigger more thinking about the pattern of the phenomenon discovered. The teacher gives instructions guardedly (Lawson Abraham \& Renner, 1989). 


\section{An Overview of Learning Cycles in Science Inquiry-based Instruction}

\section{Term Introduction}

In this phase, learners are expected to do interpretation and critical analysis of the new data collected in the exploration phase. It is a more teacher-centered phase, therefore, care and restraints should be exercised by the teacher not to reduce the lesson to a lecture as $\mathrm{s} /$ he introduces the new terminologies that describe the observations at the exploration phase (Maier \& Marek, 2006). The learners are required to create mind maps that relate the terms with the patterns developed in exploration for concrete construction of knowledge. Even though the teacher leads, the learners should as much as possible unveil as many patterns as possible before the teachers' intervention (Lawson, Abraham \& Renner, 1989).

\section{Concept Application}

Since there is more to learning than analyzing data and developing a concept derived from that data set, concept application requires that learners apply the newly accommodated concepts, terms and, or the patterns learned to many different and varying situations to buttress and authenticate the new concepts (Lawson, Abraham \& Renner, 1989). This phase is important because it expands the cognitive horizon of the learner who realizes how the pattern extends to other cases that are different from those they may have been exposed to.

According to Marek (2008), these three phases have now come to be called Explore, Explain and Elaborate or 3E. However, even with the change of name of the second and third phases, the meaning and activities associated with these phases have remained essentially unchanged. The overall goal of the first phase is to motivate the learners, while the second phase sustains the motivation by explaining the unexplained and finally, the last phase only proves the
C. B. Nicol, E. Gakuba \& G. Habinshuti extent of achievement by checking for higher cognitive reasoning in the application (Duran \& Duran, 2004). At each of the phases, the teacher does a formative evaluation. In the exploration and elaboration phases, the teacher evaluates process skills through regular comprehension checks at the Explain phase. Also, it is implied that the teacher evaluates the product, which is the solution to the given problem at hand.

For multi-level learners, both assimilation and disequilibrium are likely to occur in the exploration phase as the learners will have varying skill levels and experiences (Maier \& Marek, 2006). For instance, an unexpected observation in the course of exploration will amount to a disequilibrium as learners will begin to reexamine their conceptions. However, in the concept introduction phase, as a result of the interpretation and explanations of the data obtained in the previous phase, as well as the discussions around it, reequilibration sets in, paving way for learners to more easily accommodate the new cognitive structure. As learners are consolidating the new concept developed in the previous phase, it may be easier for them to more easily assimilate and accommodate a different cognitive structure (Gok, 2014).

The Five-phase Learning Cycle- $5 E$

While Renner, Abraham and Birnie (1988) commend the three-phase learning cycle for the logical flow of the sequence in the phases, the reasons that necessitated the BSCS elementary school curriculum review were the difficulty faced by teachers in remembering the names of the phases in the SCIS learning cycle, difficulty in achieving conceptual development in using this cycle, and more importantly, the need to grow the learning cycle into an instructional model (BSCS, 2014). The 5E model retains the three phases of the $3 \mathrm{E}$ in the middle and 
extends by two; one each at the beginning and the end. With the phases named as Engagement, Exploration, Explanation, Exploration and Evaluation, the 5E model is the most widely cited in the literature (Duran $\&$ Duran, 2004). Description of the activities in these phases is elaborated as follows.

\section{Engagement}

As the first stage in the cycle, this phase is student-centered and minds-on, intended to create and develop learners' interest, and to occupy their minds on the topic and what lies ahead in the lesson. Engagement should persuade and convince learners about the reason they should learn the topic (Dass, 2015). Dass adds that teachers should delay announcing the topic until learners have engaged in worthwhile activities that will pique their curiosity: activities such as watching a demonstration, a media clip; listening to a report, a relevant hypothetical story or engaging the class with an openended question to elicit their responses helps in bringing out learners' previous knowledge about the topic for discussion and misconceptions that they may have (Bybee, 2006; Bybee et al., 2006; Lorsbach, 2005). The goals of this phase is to create a bridge between what learners already know and the information in the new lesson (Bybee et al., 2006), and more importantly, to generate what Dass referred to as "lingering questions": subsequent activities must be planned to answer the lingering questions or finding solutions to a problem identified in this phase.

\section{Exploration}

According to Duran and Duran (2004), Exploration is a student-centered hands-on phase that is aimed at enhancing and promoting learners' process skills and critical thinking. This phase also requires that learners cultivate cooperative learning strategies. So in pairs or small groups, learners collectively investigate a concept, make discoveries, even make mistakes, ask questions to their peers and the teacher and record observations (Bybee, 2006). Learners are encouraged to do independent work as much as possible. The teacher as a guide by the side can respond to questions by asking probing questions to trigger more critical thinking. This is where, according to Piaget's theory, disequilibrium occurs to the cognitive structure of the learners as they put their hypotheses to test. Sometimes puzzling observations will be made but learners will need to suspend judgment (Lorsbach, 2005).

\section{Explanation}

This phase is a teacher-driven and students' minds - on phase. It aims to cultivate learners' correct use of scientific terms, listening and oral skills in describing the observations in the exploration phase and providing answers and solutions to the lingering questions through interactive engagement and the grasping of the content of the topic (Dass, 2015). This is where laws, principles and theories are introduced to support explanations of observations. The phase is usually divided into two; first, the students are given an opportunity to demonstrate their conceptual understanding by describing the observations made. Thereafter, the teacher steps in with the appropriate definitions, explanations and corrections (Duran \& Duran, 2004). According to Mulder (2019), supportive learning tools like videos, power-point presentations or role-plays could be used to help learners more clearly grasp the new information. Teacher models question answering as well as put emphasis on evidence for conclusion making and does a lot of comprehension checks by asking appropriate questions for formative evaluation (Eisenkraft, 2003). 


\section{An Overview of Learning Cycles in Science Inquiry-based Instruction}

\section{Elaboration}

This phase is a student-centered, hands-on and minds-on phase. The aim is for learners to directly apply and extend all the concept and skills acquired in the previous phases (Bybee, 2006; Bybee et al., 2006). Like the exploration phase, learners need to interact a lot to broaden their understanding of what has been learned. Activities may include classroom exercises, role plays or quizzes (Duran \& Duran, 2004). Eisenkraft (2003) adds that the teacher can assign a task related to those discussed in class and checks on learners' progress in applying what they have learned and provide feedback. The activities in this phase can be used as the basis for evaluation (Dass, 2015). This phase therefore gives learners who missed firmly understanding the concepts being investigated another learning opportunity.

\section{Evaluation}

Evaluation is both a separate phase and an activity that applies throughout other phases in the learning cycle (Dass, 2015). It also applies to both the learners and the teacher: the learners evaluate their learning, the teacher evaluates the learners' learning as well as his or her achievement in the classroom (Bybee et al., 2006; Bybee, 2006). As a phase, the teacher should be summing up on informal assessments of process skills and related competencies while the formal assessment techniques such as quizzes and exams are used for a more complete representative judgment of learning outcome in this summative evaluation phase. This phase demonstrates proof of instruction and learning (Duran \& Duran, 2004). It is also a time of self-reflection especially for the teacher who should reflect on what went well and what did not, and how to improve on areas that did not go well. This is imperative if errors need to be corrected and subsequent lessons improved with time.

\section{B. Nicol, E. Gakuba \& G. Habinshuti} $7 E$ Learning Cycle

The 7E model by Eisenkraft (2003) was proposed on the premise of the need to emphasize eliciting learners' prior understanding and the transfer of learning. It is an expansion of the $5 \mathrm{E}$ model and thus retains all the phases of the $5 \mathrm{E}$ but also includes two, Elicit and Extend, at the beginning and end respectively. In addition, the model as well as its inclusion of the Elicit phase is justified by reference to the research literature on cognitive science that supports eliciting prior knowledge for worthwhile learning (Eisenkraft, 2003). The phases are listed as Elicit, Engage, Explore, Explain, Elaborate, Evaluate and Extend. The first phase, Elicit, is an expansion of the Engagement phase in 5E. Therefore, in place of Engagement in 5E, are now Elicit and Engage. According to Eisenkraft, the Elicit phase draws teachers' attention to the need for information on the learners' prior knowledge on the topic for instruction to serve as the basis for further actions in the Engagement phase. Similarly, the last, Extend, is a protraction of the Elaboration and Evaluation stages of the 5E, which emphasizes the need for learners to transfer, outstretch and apply the acquired knowledge and skills to different contemporary everyday experiences.

\section{E Learning Cycle}

The phases of the 9E learning cycle are; Elicit, Engage, Explore, Explain, Echo, Elaborate, Evaluate, Emend and E-search. Apart from having nine phases, the 9E learning cycle proposed by Kavur and Gakhar (2014), positions E-Search at the center of the cycle, implying the use of electronic search at every of the eight other phases. Besides, the 9E introduces new terms to represent two phases; Echo and Emendation. The Echo phase merely emphasizes more practice by learners in the 
classroom in addition to the Elaboration activities, whereas Emendation serves to complete the cycle of the day's lesson by correcting misconceptions and errors that may have still been carried along in the lesson. In essence, it attempts to close the gap on erroneous views held by learners. The other six phases also common to the previously discussed models describe essentially the same activities.

\section{Empirical Evidence in Support of the Learning Cycle Model of Teaching}

Overwhelming empirical evidence supports the effectiveness of the learning cycles generally. As one of those who have worked extensively on learning cycles, Marek (2008), indicates that the learning cycle helps learners conceive the right attitudes and ideas, as well as improves their reasoning ability through meaningful engagement. Ajaja and Eravwoke (2012) finds that the learning cycle was a remedy for problems associated with science teaching methods because it presents knowledge coherently and systematically. In this way, knowledge acquired is more permanent. This is why Ross and Cartier (2015) referred to the learning cycle as a 'support mechanism' since many teachers experience tremendous challenges in planning lessons that allow learners an opportunity to engage in meaningful science learning activities (Ross \& Cartier, 2015). The exciting thing about the learning cycle is that it makes possible self - evaluation by learners (Quarareh, 2015). In a study conducted by Ceylan (2008) it was confirmed that the $5 \mathrm{E}$ instructional model enhances improvement in the acquisition of scientific concepts as well as learners' positive attitude, while teacher training in the $5 \mathrm{E}$ model was found to promote active learning (Alshehri, 2016).

A study by Sam, Owusu and AnthonyKrueger (2018) indicated that while there was a significant difference in the academic performance in favor of learners taught using the learning cycle models and the traditional lecture method, no significant difference was observed in academic performance of learners who were instructed using the 5E and 3E models. Apart from the superiority of the learning cycle demonstrated in this study, it may suggest that the strength of the learning cycle actually lies in the sequence of the three original phases that constitute the $3 \mathrm{E}$ in a way that the Engagement and Evaluation phases have relatively lesser contribution to the overall learning success. Even so, a comprehensive empirical study that evaluates not only the $5 \mathrm{E}$ and $3 \mathrm{E}$ but other learning cycles need to be conducted to inform the research community.

A handful of researches on the effectiveness of the 7E have also been conducted with a favorable outcome for learning achievements. Adesoji and Idika (2015) concluded that the 7E learning cycle and the case-based strategy to teaching were very effective in enhancing academic achievement and positive attitudes of senior high school learners of chemistry. Similarly, Balta and Sarac (2016) who studied the effect of the 7E learning cycle model on the teaching of science subjects concluded in favor of the model as having a higher effect size on learning. In another study that looked at the impact of worksheet on Newton's laws of motion using the 7E model of instruction, it was found to enhance conceptual understanding and problem solving (Primanda, Distrik \& Abdurraman, 2018). Although the proponent of the 9E Learning Cycle model found it to be very suitable for effective students' learning, there is yet very little literature in support of this claim.

\section{Discussion}

The Learning Cycle in its various forms has essentially three main goals, which are, 


\section{An Overview of Learning Cycles in Science Inquiry-based Instruction}

C. B. Nicol, E. Gakuba \& G. Habinshuti

developing learners' conceptual understanding, their process skills and critical thinking. These are the most desired competencies every learner must long for, and every teacher must strive to impart. All of the Learning Cycles considered in this paper are indicated to have these key needs. While the $3 \mathrm{E}$ learning cycle laid the very basis for interesting active learning environment, it suggests a lesson without a purposeful minds-on engagement between learners and teachers: a brief questioning session at the beginning of the lesson sets the right tone and activates cognitive processes in learners.

This is in fact supported by the generative theory of learning which emphasizes cognitive over behavioral activity for promoting learning (Mayer et al., 2009). The only means of motivating students is by the exploration. Mulder (2019) explains that learners would be motivated and their interest piqued more if the lesson started with a question about a relevant story or a display of an object or a diagram about which they need to think and process the information in their minds to provide independent divergent answers. This sets the stage for more learner immersion into the lesson thus enhancing greater cooperation and readiness for acquiring new information by exploration.

This gap was worth covering by BSCS' inclusion of the Engagement phase that precedes exploration in the $5 \mathrm{E}$ model. The $5 \mathrm{E}$ has been the most widely cited among learning cycles because it seems to provide adequate active learning engagement for science teaching. As questions naturally result from curiosity and leads to acquisition of knowledge, teachers must demonstrate flexibility for an organized engagement in questions and answers between learners and between learners and teachers at every phase of the cycle. In addition, acknowledging that evaluation does not mark the end of the cycle, teachers ought to create a smooth transition between previous and current lesson.

Worth noting is the fact that the need to obtain learners' prior knowledge is not absent in the $5 \mathrm{E}$ as it is confirmed by Eisenkraft (2003 57) "The Engage component of the $5 \mathrm{E}$ model is intended to capture students' attention, get students thinking about the subject matter, raise questions in students' minds, stimulate thinking and access prior knowledge ". This suggests that a well thought - out and properly implemented 5E teaching model may not need to have an Elicit phase which only serves to remind teachers. We hold the view that increasing the number of phases in the learning cycle should not be for the sake of reminding teachers of what the phase is indicated to achieve. Brevity in instructional phases may be beneficial to the teacher, teaching and learner. In our view, the fewer the number of phases, the greater the likelihood of maintaining and sustaining learners' interest in the lesson, the better learners can retain the details of activities at every phase and the greater the chances of completing a cycle of activity. In essence, elicitation in both the 7E and 9E models can be embedded in, and enhanced through the Engagement phase.

We believe that it will serve an important purpose to include the Extend phase after Evaluation. This will comprise homework and other out-of-class assignments with the sole objective of applying the concepts to related contexts. It is more important that it stands alone to emphasize to teachers the need to assign a task to learners at the end of the lesson; one that will require them to apply what they learnt to their experiences outside of the classroom.

Apart from the greater number of phases in the cycle which might amount to a difficulty 
in remembering the names, one obvious drawback of the $9 \mathrm{E}$ model is its heavy dependence on technology. While technology may excite learners and make learning interesting, it may not serve an overall good and achievable purpose if it were to made a compelling part of a universal teaching model in the way it is presented. The absence of it in the phases of a learning cycle should not be a hindrance to teaching and the achievement of learning in the developing countries that barely meet acceptable standards for universal education. In fact, as suggested by Reiff et al. (2002), at the center of every learning cycle inquiry instructional model must be "Questions", which is more important to learning than an electronic search.

With the introduction of the Echo phase between Explain and Elaborate, the proponents of the 9E emphasize more practices and correction of errors and misconceptions in the lesson. However, a well-planned lesson will rather include more and diverse types of practices and exercises in the elaborate phase than have two different and separate phases dedicated to achieving the same goal. While Emendation is a critical part of every good lesson as it ensures summary and closure, where corrections are based on misconceptions, and as clearly stated, the teacher can also do "polishing the methods of teaching as well as learning (Kavur and Gakhur 2014, 343)". However, regular comprehension checks throughout the preceding phases would have eliminated misconceptions before the last phase of the cycle. It may be embedded in, and considered a part of summative evaluation. The teacher could even ask learners to summarize the major learning points of the lesson or ask carefully designed questions meant to meet this objective.

It is worth noting that the number of phases in the learning cycle could either aid or hamper its effective and practical implementation in the classroom. A learning cycle that comprises many phases can be a cause of the teachers skipping some phases either by design or through forgetfulness thus hampering the overall objective of instruction. This may even affect its preference as a desirable model for practical teaching in a 40 or 45-minute lesson.

\section{Conclusion}

This overview of learning cycles in science inquiry instruction was set to evaluate four models; the 3E, 5E, 7E and 9E learning cycles. The learning cycle in scientific inquiry is built upon three fundamental phases which are exploration, explanation and elaboration as these represent the obvious basic stages in learning. While the $3 \mathrm{E}$ is definitely an important reference upon which several modifications and expansions have been made, it does not provide room for initial dialogic engagement of learners with their teachers, where their previous knowledge is elicited and misconceptions identified, upon which new knowledge is built. The $5 \mathrm{E}$ model partly addresses this inadequacy in its Engagement phase. This makes the elicit phase of the $7 \mathrm{E}$ learning cycle redundant: the learning cycles may not need to have a separate elicit phase if it has an engagement phase, as is the case with the $5 \mathrm{E}$ since the Engagement phase also serves to unveil misconceptions and to remind teachers about the need to probe into previous understanding of learners. However, the Extend phase of the 7E cycle is critical to learning. The need for learners to extend their acquired knowledge after is backed by theory and practice and therefore warrants inclusion in the learning cycle.

Similarly, since the goal of the Echo and Emend phases of the 9E learning cycle are reflected in the Elaboration and Evaluation respectively, their inclusion may not amount to a critical necessity. A "search" at every 


\section{An Overview of Learning Cycles in Science Inquiry-based Instruction}

phase is highly important since the learning cycle is an inquiry-based instructional model. Nonetheless, an electronic search may not be the realistic way of a teaching and learning model for the present-day universal application. Therefore, after a thorough need assessment of the phases of the learning cycles under review, a sixphase learning cycle is proposed comprising the phases; Engage, Explore, Explain, Elaborate, Evaluate and Extend. An important implication from these conclusions is that the learning cycles may continue to evolve, therefore, newer learning cycles should be subjected to validation. Second, further empirical studies of the sixphase learning cycle is recommended in order to establish its effectiveness in enhancing learning.

\section{Acknowledgement}

We are indebted to resourceful colleagues in persons of Messers Joseph Njiku and Adejimi Saheed for proofreading the manuscript and making valuable contributions that resulted in the final structure and content of this paper.

\section{References}

Abraham, M. R., \& Renner, J. W. (1986). The sequence of learning cycle activities in high school chemistry. Journal of Research in Science Teaching, 23(2), 121-143.

Abraham, M. R., \& Renner, J. W. (1988). The sequence of learning cycle activities in high school chemistry. Journal of Research in Science Teaching, 23(2), 121-143.

Abraham, R. (1997). The learning cycle approach to science instruction. University of Oklahama, Department of Chemistry and Biochemistry. Norman: NARST.
C. B. Nicol, E. Gakuba \& G. Habinshuti Adesoji, F. A., \& Idika, M. I. (2015). Effect of 7E learning model and case- based learning strategy on secondary school studens' learnig outcomes in chemistry. JISTE, 19(1), 7-17.

Ajaja, P. O., \& Eravwoke, U. O. (2012). Effects of $5 \mathrm{E}$ learning cycle on students' achievement in biology and chemistry. Cypriot Journal of Educational Science, 7(3), 244-262.

Alshehri, M. A. (2016). The impact of using (5e's) instructional model on achievement of mathematics and retention of learning among fifth grade students. Journal of Research \& Method in Education, 6(2), 43-48.

Balta, N., \& Sarac, H. (2016). The effect of $7 \mathrm{E}$ learning cycle on learning in science teaching: A meta- analysis study. European Journal of Educational Research, 5(2), 61- 72.

Brown, P. L., \& Abell, S. K. (2007). Examining the learning cycle. Science and Children, Vol 55, issue 5 58-59.

BSCS (2014, December 9). The BSCS 5E Instructional Model(part1): Creating the 5E Model[video].

Youtube.http://www.youtube.com/w

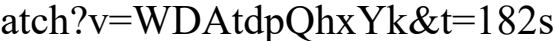

Bybee, R. W. (2006). The high school curriculum reflection: Reflection on teaching and learning. Full Report Prepared for the Office of Science Education National Institute of Health, Colorado Spring Biological Science Curriculum Study.

Bybee, R. W., J.A. Taylor., A. Gardener., P.V. Scotter., J.C. Powell, and A. L. Westbrook. (2006). The BSCS 5E instructional model: origins, effectiveness and application. AA 
African Journal of Educational Studies in Mathematics and Sciences Vol. 16, No. 2, 2020

report prepared for the office of science education. National institute of health. June 12, 2006.

Bybee, R. W. (2006). The high school science curriculum : Reflection on teaching and learning. Full report prepared for the office of science education national institute of health. Colorado: Biological Science Curriculum Study (BSCS).

Cavallo, A. M., \& Laubach, T. A. (2001). Students' science perceptions and enrollment decisions in differing learning cycle classrooms. Journal of Research in Science Teaching, 38(9), 1029-1062.

Ceylan, E. (2008). Effect of $5 E$ learning cycle model on understanding of state of matter and solution concepts. Unpublished doctoral dissertation. Middle East Technical University, Turkey.

Dass, P.M. (2015). Teaching STEM effectively with the learning cycle approach. K - 12 STEM Education. $\operatorname{Re1}(1), 5-12$

DeBoer, G. E. (2006). Historical perspectives on inquiry teaching in schools. Scientific Inquiry and Nature of Science, 25, 17-35.

Duran, L. B., \& Duran, E. (2004). The 5E instructional model: a learning cycle approach for inquiry-based science teaching. The Science Education Review, 3(2), 49-58.

Eisenkraft, A. (2003). Expanding the 5E model. The Science Teacher, 70(6), 56.

Gok, G. (2014). The effect of 7e learning cycle instruction on 6th grade ctudents' conceptual understanding of humanbody systems, selfregulation,scientific epistemological beliefs and science process skills. Middle East Technical University: Ankara, Turkey.

Good, R., \& Lavoie, D. (1986). The importance of prediction in science learning cycles. Journal of the Florida Associationof Science Teachers, 1(4), 24-35.

Hanley, C. D. (1997). The effects of learning cycle on the ecological knowledge of general biological studies as measured by two assessment techniques. Unpublished doctoral dissertation: University of Kentucky, USA.

Hanuscin, D. L. and M. H. Lee. 2008. Using the Learning Cycle as a model for teaching the learning cycle to preservice elementary teachers. Journal of Elementary Science Education. 20(2), 51-56

Karplus, R., \& Their, D. H. (1967). A new look at elemenatry school science. Chicago: Rand McNally.

Karplus, R., Lawson, A. E., Wollman, W., Appel, M., Bernoff, R., Howe, A., . . - Sullivan, F. (1977). Science teaching and the development of reasoning: A workshop. Berkeley: Regents of the Univeristy of California.

Lawson, A. E. (1988). A better way to teach biology. American Biology Teacher, 266-289.

Lawson, A. E., \& Renner, J.W (1975). Relationships of science subject matter and developmental levels of learners. Journal of Research in Science Teaching, 347-358.

Lawson, A. E., Abraham, M. R., \& Renner, J. W. (1989). A theory of instruction: Using the learning cycle to teach science concepts and thinking skills. 
An Overview of Learning Cycles in Science Inquiry-based Instruction

C. B. Nicol, E. Gakuba \& G. Habinshuti

Kansas State Univertsity. Manhattan: National Association for Research and Science Teaching.

Lorsbach, A. W. (2005). The learning cycle as a tool for planning science instruction.

Islandora.mlml.calstate.edu.

September 20. Accessed September 14, 2019. http://www.coe.ilstu.edu/scienceed/1 orsbach/257lrcy.htm.

Maier, S. J., \& Marek, E. A. (2006). The learning cycle: A reintroduction. The Physics Teacher, 44, 109-113. doi:10.1119/1.2165443

Marek, E. A. (2008). Why the learning cycle? Journal of Elementary Science Education, 3, 63-69.

Richard E. Mayer, A. Stull., K. DeLeeuw., K. Almeroth., B. Bimber., D. Chun., M. Bulger., J. Campbell., A. Knight., H. Zhang. 2009. Clickers in college classrooms: Fostering learning with questioning methods in large lecture classes. Contemporary Educational Psychology, 34: 51-57

Mulder, P. (2019, October 6). 5e instructional model. Retrieved from toolshero:

http:www.toolshero.com/effectivene ss/5e-instructional-model

Odom, A. L., \& Kelly, P. V. (2001). Integrating concept mapping and the learning cycle to teach diffusion and osmosis concepts to high school biology students. Science Education, 85, 615-635.

Piaget, J. (1953). Genetic psychology and epistemology. Diogenes, 1(1), 4963.
Powell, K., \& Kalina, C. J. (2009). Cognitive and social constructivism: Developing tools for an effective classroom. Education, 130(2), 241250.

Kaur, P., \& Gakhar, A. (2014). 9E model and e-learning methodologies for the optimisation of teaching and learning. International Conference on MOOC Innovation and Technology in Education (MITE). Patiala, India: IEEE. 342347.

Primand, A., Distrik, W. I., \& Abdurrahman. (2018). The impact of 7E learning cycle-based worksheets toward students conceptual understanding and Problem Solving Ability on Newton's Law of Motion. Journal of Science Education, 2(19), 95-106. Retrieved from http://chinakxjy.com

Qarareh, A. O. (2012). The effect of using the learning cycle method in teaching ecience on the educational achievement of the sixth graders. International Journal of Educational Sciences, 4(2), 123-132.

Ramsey, J. (1993). Developing conceptual storylines with the learning cycle. Journal of Elementary Science Education, 5(2), 1-20.

Reiff, R., Harwood, W. S., \& Phillipson, T. (2002). A sientific method based upon research scientists' conceptions of scientific inquiry. Annual International Conference of the Association of Teachers in Science (pp. 1-25). NC: Association for the Education of Teachers in Science.

Renner, J. W., \& Marek, E. A. (1988). The learning cycle and elementary school science teaching. Portsmouth, NH: Heinemann Educational. 
African Journal of Educational Studies in Mathematics and Sciences Vol. 16, No. 2, 2020

Renner, J. W., Abraham, M. R., \& Birnie, H. (1988). The neccesity of each phase of the learning cycle in teaching high school physics. Journal of Research in Science Teaching, 25(1), 39-58.

Richardson, V. (2003). "Constructivist pedagogy.". Teachers College Record, 105(9), 1623-1640.

Ross, D. K., \& Carter J.L (2015). Developing Pre-service Elementary Teachers' Pedagogical Practices While Planning Using the Learning Cycle. Journal of Science Teacher Education. 26:573-591

Sam, C. K., Owusu, K. A., \& Anthony, C. (2018). Effectiveness of 3E, 5E and conventional approaches of teaching on students' achievement in high school biology. American Journal of Educational Research, 6(1), 76-82.

Settlage, J. (2000). Understanding the learning cycle: Influences on abilities to embrace the approach by preservice elementary school teachers. Science Teacher Education, 84, 43-50.

Suardana, I. N., Redhana, I W., Sudiatmika, A. A. I. A. R., \& Selamat, I N. (2018). Students' Critical Thinking Skills in Chemistry Learning Using Local Culture-Based 7E Learning Cycle Model. International Journal of Instruction, 11(2), 399412.

https://doi.org/10.12973/iji.2018.11 $227 \mathrm{a}$

Sweller, J. (2003).Evolution of human cognitive structure. In B. Ross(Ed.), The psychology of Learning and Motivation. 43.215-266. San Diego, CA: Academic

Withers, M. 2016. The College Learning Cycle: An instructional model for reformed teaching. CBE-Life Science Education. 15:es12, 1-12. http://www.lifescied.org/ 

African Journal of Educational Studies in Mathematics and Sciences Vol. 16, No. 2, 2020

Open Access article distributed under the terms of the Creative Commons Attributions License [CC BY-NC-ND 4.0] http://creativecommons.org/licenses/by-nc-nd/4.0. DOI: https://dx.doi.org/10.4314/ajesms.v16i.2.5 